専門医症例報告

\title{
インプラントを用いて咬合支持を再建した下顎片側遊離端欠損症例
}

鮎川 保則

\section{Mandibular Unilateral Free-end Missing Reconstructed by Implant Prosthesis}

\author{
Ayukawa Yasunori
}

抄 録

症例の概要：患者は 58 歳の女性.下顎右側大臼歯欠損と上顎右側臼歯部ブリッジ脱離による咀嚼障害の 治療を希望して来院した。下顎大臼歯部はインプラントを支台としたハイブリッドセラミックス前装鋳造 冠を用いた補綴治療を行った。同時に 7 歯肉縁下の二次う触や，同歯挺出によるクリアランス狭小化に配 慮しつつ 75 を支台歯としたブリッジによる補経を行った。 4 年以上経過したが，その間 5 遠心に歯間離 開を生じたため, 同歯の補緅装置再作製にて対応した.

考察：離開は天然歯の生理的移動により生じたと考えられた. 今後さらに観察していく必要がある.

結論：片側遊離端欠損症例に対し，インプラントを用いて咬合支持を再建することができた.

和文キーワード

インプラント, 片側遊離端欠損, 生理的歯牙移動

\section{ABSTRACT}

Patient: A 58-year-old woman presented with a chief complaint of masticatory dysfunction caused by the missing of lower right molars and the detachment of fixed partial denture at the upper right molar region. For this case, implant-retained fixed partial denture with hybrid ceramics facing cast crowns for lower right molar region and conventional fixed partial denture for upper right molar region, considering both the secondary caries and the extrusion of upper right second molar, were fabricated. The patient was followed for $>4$ years after treatment, and separation between mandibular implant prosthesis and the lower right second premolar was observed during the follow-up period. The interdental separation was treated by refabrication of the prosthesis of the second premolar.

Discussion: Physical teeth movement may cause separation between natural tooth and implant-retained prosthesis.

Conclusion: Functional problems caused by the loss of occlusal support were successfully rehabilitated using implant-retained fixed partial denture.

\section{Key words}

implant, unilateral free-end missing, physical tooth movement

九州大学大学院歯学研究院口胿機能修復学講座咀嚼機能再建学分野

Section of Removable Prosthodontics, Division of Oral Rehabilitation, Faculty of Dental Science, Kyushu University

受付：2007 年 10 月 26 日/受理：2008 年 5 月 5 日

Received on October 26, 2007/Accepted on May 5, 2008 


\section{I. 緒言}

遊離端欠損は, 前歯部の負担過重や対合歯の挺出, 可撤性義歯により補緅を行った場合の支台歯の負担， 大連結子による舌感や発音への影響等，種々の問題 点を生じることが多い. 下顎片側遊離端欠損を放置 したために対合歯が挺出している症例に対し，インプ ラントを用いて咬合支持を再建し，4 年間にわたる良 好な結果を得たので報告する。

\section{II. 症例の概要}

患者：初診時年齢 58 歳，女性

初診 : 2000 年 5 月

主訴：右下に歯がなく, 加えて右上のブリッジがは ずれたので噛めない.

既往歴：甲状腺良性腫瘍（1980 年に摘出手術を受 け，術後の経過は良好である。現在定期検診のみで 治療は行っていない)

家族歴：特記事項なし

全身状態：特記事項なし

現病歴：1997 年頃, 近医にて下顎右側大臼歯欠損 に対して部分床義歯治療を受けたが，リンガルバー による違和感のため部分床義歯を使用せず，欠損部 を放置していた，2000 年 1 月頃，下顎左側小臼歯間 の食片圧入が気になるようになり，さらに 3 月になっ て同部の冷水痛にて当病院保存科を受診, 45 および 44 のう触処置 (インレー装着)を受けた。その際上記 主訴に対する治療を希望し，当科を受診した。

現症 : 初診時の口腔内写真とパノラマ $\mathrm{X}$ 線写真を 図 1 と図2に示す. (7)6 5) 部に装着されていたブリッ ジは脱離していたが，保存科主治医によって暫間的に 仮着がなされていた. Eichnerの分類は B1 であった. また, 下顎右側大臼歯部は欠損であったが, 補綴装置 を装着せず放置していたためか 7 が挺出しており， 同歯の歯頸部にう蝕と歯肉の炎症が認められた。さ らに，挺出した 7 と対合顎堤間のクリアランスは非常 に狭小であった。また， 17 に装着された全部鋳造冠 の腐食が観察された。歯周組織検査ではプロービン グデプスが $3 \mathrm{~mm}$ を超える歯を 4 本（7」，|67， 7 ） 認めた（表 1 ).

診断： 76 欠損による咀嚼障害および 7 挺出によ る咬合平面の不正.

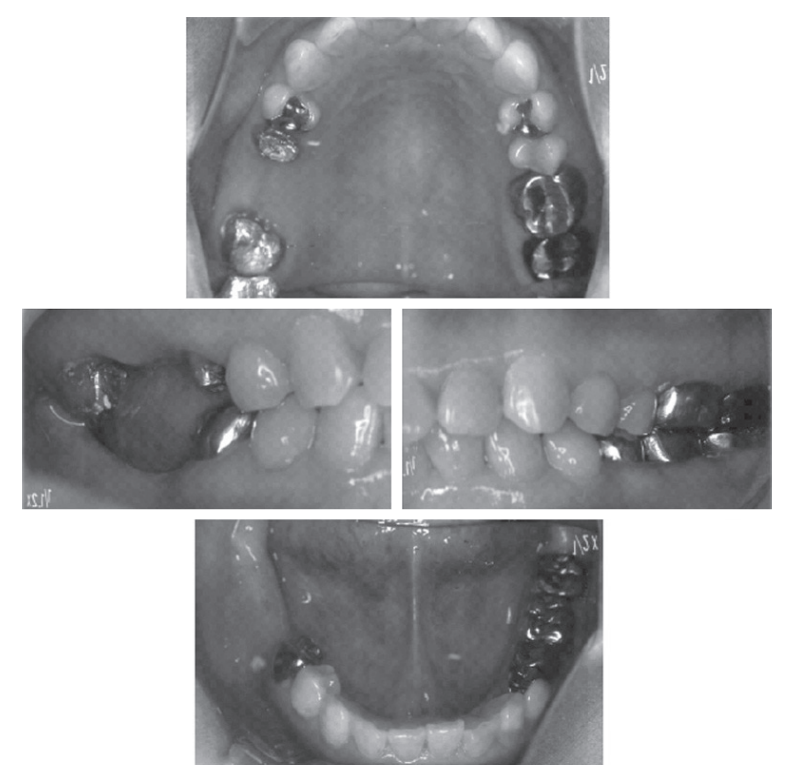

図 1 Intraoral views at the first examination 初診時の口腔内写真

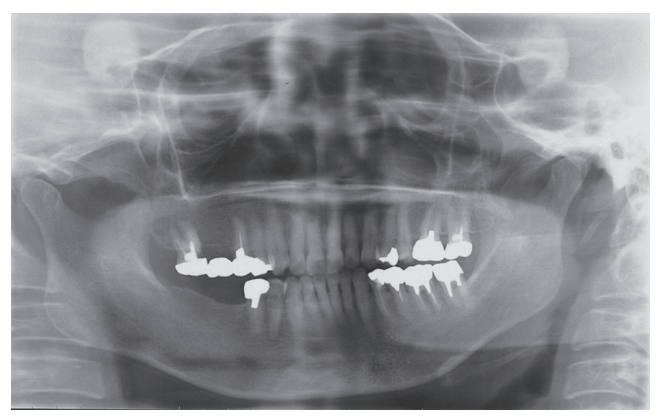

図 2 Panoramic radiograph at the first examination 初診時のパノラマ X 線写真

\section{III. 治療内容と経過}

\section{1. 治療内容}

治療に先立ち,インフォームドコンセントを行った。 軽度〜中程度の歯周疾患がみられるため, この治療 を欠損補綴に先立って行うこと, 久損部の治療方法 としては下顎では可撤式の部分床義歯あるいはインプ ラントがあり，上顎では加えてブリッジも可能である ことを説明した．患者が特に違和感の問題より可撤 性の補綴装置を希望しなかったことと，下顎右側部 の可撤性義歯以外の治療に際して自費の負担を承諾 いただいたため，上顎はブリッジ，下顎はインプラン 卜を用いた欠損補綴を行うことで患者の同意を得た. また，7」挺出と歯肉縁下カリエスのため，歯冠長延 
表 1 Periodontal conditions at June (upper) and September (lower), 2000

歯周組織検査，上：2000 年 6 月，下：2000 年 10 月

\begin{tabular}{|c|c|c|c|c|c|c|c|c|c|c|c|c|c|c|c|c|c|c|c|c|c|c|c|c|c|c|c|c|c|c|c|c|c|c|c|c|}
\hline \multirow{2}{*}{ ポケットの深さ } & 㚘側 & & 3 & \begin{tabular}{l|l}
4 & 4 \\
\end{tabular} & & 2 & 2 & 2 & 2 & \begin{tabular}{l|l}
1 & 1 \\
\end{tabular} & \begin{tabular}{l|l}
1 & 1 \\
\end{tabular} & & 2 & 1 & \begin{tabular}{l|l|l}
1 & 1 \\
\end{tabular} & 1 & 1 & 2 & 2 & 12 & 3 & 1 & & & & 1 & & & & 2 & & & \begin{tabular}{|l|l|}
4 & 4 \\
\end{tabular} & & 4 & \\
\hline & 口蓋側 & & 3 & \begin{tabular}{l|l|}
2 & 3 \\
\end{tabular} & & 3 & 2 & 3 & \begin{tabular}{l|l}
3 \\
\end{tabular} & \begin{tabular}{l|l}
2 & 2 \\
\end{tabular} & $\begin{array}{ll}2 & 1 \\
\end{array}$ & 1 & 2 & 2 & \begin{tabular}{l|l}
1 & 2 \\
\end{tabular} & 2 & 1 & 2 & 2 & $\begin{array}{ll}12 \\
\end{array}$ & & 2 & 2 & $2 \mid$ & $2 \sqrt{2}$ & 2 & 2 & 233 & & 2 & 4 & \begin{tabular}{l|l}
2 & 3 \\
\end{tabular} & \begin{tabular}{|l|l|}
3 & 3 \\
\end{tabular} & & 3 & \\
\hline & & 8 & & 7 & 6 & & 5 & & & 4 & & 3 & & & 2 & & 1 & & & 1 & & 2 & & & 3 & & 4 & & 5 & & & 6 & & 7 & & 8 \\
\hline & & 8 & & 7 & 6 & & 5 & & & 4 & & 3 & & & 2 & & 1 & & & 1 & & 2 & & & 3 & & 4 & & 5 & & & 6 & & 7 & & 8 \\
\hline \multirow{2}{*}{ ポケットの深さ } & 舌側 & & & & & 2 & 2 & 3 & 2 & \begin{tabular}{l|l}
2 & 2 \\
\end{tabular} & $2 \sqrt{2}$ & 1 & 2 & 1 & \begin{tabular}{l|l}
1 & 1 \\
\end{tabular} & 1 & 1 & 1 & 1 & \begin{tabular}{l|l|l|}
1 & 1 \\
\end{tabular} & 1 & 1 & 1 & 2 & 12 & 2 & 2 & 2 ? & & 2 & & \begin{tabular}{l|l}
2 & 2 \\
\end{tabular} & \begin{tabular}{|l|l|}
2 & 2 \\
\end{tabular} & & 3 & \\
\hline & 㚘側 & & & . & & 1 & 1 & 1 & 1 & \begin{tabular}{l|l}
1 & 1 \\
\end{tabular} & \begin{tabular}{l|l}
1 & 1 \\
\end{tabular} & 1 & 2 & 1 & \begin{tabular}{l|l}
1 & 2 \\
\end{tabular} & 1 & 1 & 2 & \begin{tabular}{l|l}
2 & \\
\end{tabular} & \begin{tabular}{l|l|l}
1 & 1 \\
\end{tabular} & 2 & 1 & 2 & 2 & 12 & 2 & 1 & \begin{tabular}{l|l}
3 & 2 \\
\end{tabular} & 22 & 3 & & \begin{tabular}{l|l}
2 & 2 \\
\end{tabular} & \begin{tabular}{|l|l|}
2 & 2 \\
\end{tabular} & & 5 & \\
\hline \multirow{2}{*}{ ポケットの深さ } & 瀬側 & & 3 & \begin{tabular}{l|l}
4 & 4
\end{tabular} & & 2 & 2 & 3 & 1 & \begin{tabular}{l|l}
1 & 2 \\
2
\end{tabular} & \begin{tabular}{l|l}
2 & 1
\end{tabular} & 1 & 1 & 1 & $1 \mid 1$ & 1 & 1 & 1 & 1 & \begin{tabular}{l|ll}
1 & 1 \\
$r$
\end{tabular} & 1 & 1 & 1 & 1 & 12 & 1 & 1 & 2 & & 12 & 2 & \begin{tabular}{l|l}
3 & 3 \\
\end{tabular} & \begin{tabular}{l|l}
3 & 2
\end{tabular} & & 3 & \\
\hline & 口蓋側 & & & \begin{tabular}{l|l}
2 & 2 \\
\end{tabular} & & 2 & & 2 & 2 & 152 & 222 & 2 & 2 & 2 & \begin{tabular}{l|l}
2 & 2 \\
\end{tabular} & 2 & 1 & 2 & 1 & \begin{tabular}{l|l}
1 & 1 \\
\end{tabular} & 2 & & 2 & 2 & 111 & & 1 & $2:$ & & 2 & & \begin{tabular}{l|l}
1 & 2 \\
\end{tabular} & \begin{tabular}{l|l|}
2 & 2
\end{tabular} & & 2 & \\
\hline & & 8 & & 7 & 6 & & 5 & & & 4 & & 3 & & & 2 & & 1 & & & 1 & & 2 & & & 3 & & 4 & & 5 & 5 & & 6 & & 7 & & 8 \\
\hline & & 8 & & 7 & 6 & & 5 & & & 4 & & 3 & & & 2 & & 1 & & & 1 & & 2 & & & 3 & & 4 & & 5 & 5 & & 6 & & 7 & & 8 \\
\hline \multirow{2}{*}{ ポケットの深さ } & 舌側 & & & & & 1 & 1 & 2 & 2 & 152 & 22 & & 2 & 2 & \begin{tabular}{l|l}
1 & 1 \\
1
\end{tabular} & 1 & 1 & 1 & 1 & \begin{tabular}{l|l}
1 & 1 \\
\end{tabular} & 1 & & 1 & & & & & 1 & & & & \begin{tabular}{l|l}
2 & 2 \\
\end{tabular} & \begin{tabular}{l|l}
2 & 2 \\
\end{tabular} & & 2 & \\
\hline & 澬側 & & & & & 2 & & 2 & 1 & \begin{tabular}{l|l}
1 & 1 \\
1
\end{tabular} & \begin{tabular}{l|l}
1 & 1
\end{tabular} & 1 & & & \begin{tabular}{l|l}
1 & 2
\end{tabular} & 2 & 1 & 2 & 1 & \begin{tabular}{l|l}
1 & 1
\end{tabular} & & \begin{tabular}{|l|} 
\\
\end{tabular} & 1 & 1 & 11 & & 1 & 2 & \begin{tabular}{l|l}
2 & 1
\end{tabular} & 2 & & 12 & \begin{tabular}{l|l}
2 & 2
\end{tabular} & & 2 & \\
\hline
\end{tabular}
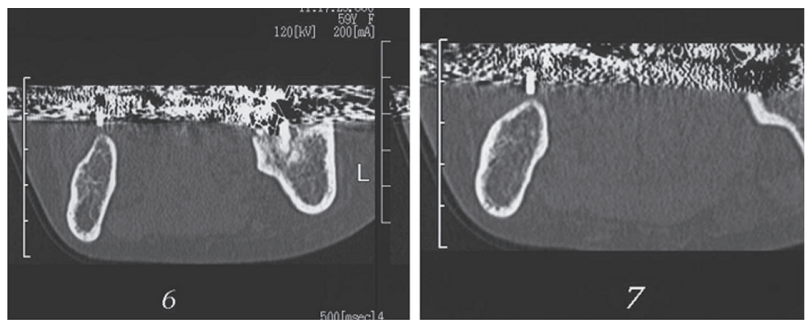

図 3 Computed tomography radiographs of $\overline{6}$ and 77 area before the implantation

76 部インプラント術前 CT 写真

長術を施行した方が良好な予後が期待できる旨説明 し，これについても同意を得た。 17 についても，全 部鋳造冠を再製作することとした，以降，歯周基本治 療を行い，7死除きプロービングデプスが $3 \mathrm{~mm}$ 以 下となったことを確認した (表 1$)$. 歯周治療開始と 同時期に 75 に装着されていたメタルコアを除去し， 感染根管治療を行った。感染根管治療終了後, 同歯 を金銀パラジウム合金による支台築造後，テンポラ リーブリッジを装着した，7沙しいては引き続き，歯 肉縁下に達するう蝕治療を行うため, また歯冠長を確 保する目的で外科的歯冠長延長術を行った，術後， 同歯のプロービングデプスは $3 \mathrm{~mm}$ 以下に改善した. $\overline{76}$ については，パノラマX 線写真および CT 写真 （図 3）よりインプラント埋入方向および距離を決定し, Steri-Oss THD HL インプラント（直径 $3.8 \mathrm{~mm}$, 長さ $12 \mathrm{~mm}$ ，チタンプラズマスプレー処理）を各部位に 1 本 ずつ埋入した（図 4)。治瘉期間は通例どおり 3 力月に 設定したが，患者都合により一次手術の 5 カ月後に 二次手術を行い, インプラント体に暫間上部構造を

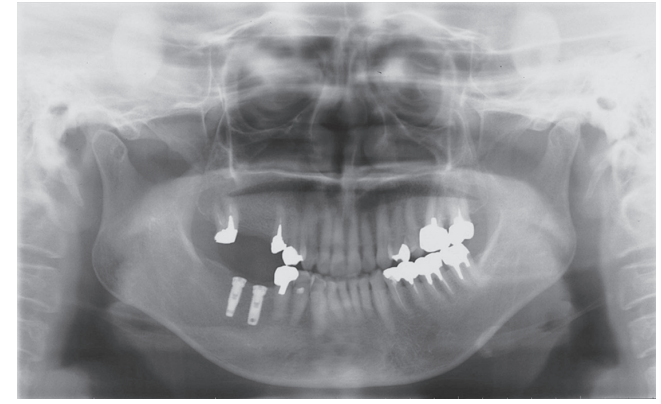

図 4 Panoramic radiograph at the implantation $\overline{76}$ 部インプラント埋入時のパノラマ X 線写真

装着した。この際，右側臼歯部における 7 挺出によ る咬合平面の不正については, インプラントの暫間上 部構造の咬合平面を 5 咬合面と臼後結節の 2 分の 1 の高さを結んだ線に合わせて設定し, 対合歯に装 着したテンポラリーブリッジの咬合面は下顎に合わ せて改善した。この状態で経過観察を行い, (7) 6 (5) および $\mid 7$ に $12 \%$ 金銀パラジウム合金製の鋳造補綴 装置を, 76 についてはハイブリッドセラミックス (Belleglass ${ }^{\mathrm{TM}}$, Sybron Dental Specialites) 前装鋳造 冠を装着し（図 5), 治療を終了した。咬合様式は, 残存天然歯の骨植に問題が認められなかったため, 臼歯離開咬合とした。

\section{2. 経過}

補綴装置装着後 1 力月は週 1 回の来院時に調整を 行い，その後月 1 回のメンテナンスに移行した。 1 年 経過後半年に 1 回のリコールに移行し, 現在に至る. リコール時には，スクリューのゆるみ，プラークコン トロール，咬合状態についてロ腔内で確認し，さらに 


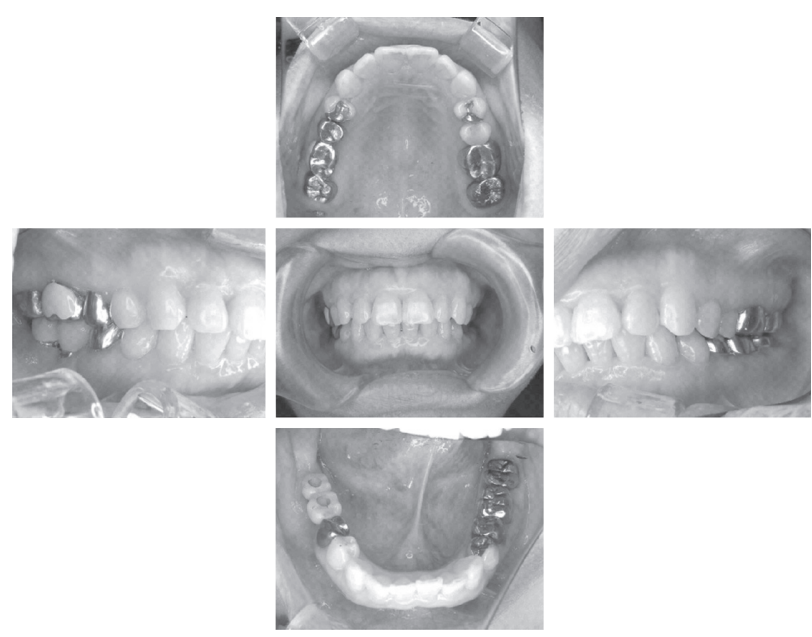

図 5 Intraoral views after 3 years and 2 months of treatment

補綴装置装着後 3 年 2 力月経過時の口腔内写真

X 線写真によってインプラント周囲骨の変化を観察 している。経過観察中, $\overline{65}$ 間に歯間離開を生じたた め（図 6)，5補緅装置再作製にて対応した（図 7). 補緅装置は, $\overline{6}$ との接触点の摩耗を最小限にする目 的で, $\overline{6}$ と同じ材料で作製した，その後，現在まで 特記すべき変化はなく，良好に経過している.

\section{IV. 考察}

本症例では，経過観察中に $\overline{65}$ 間に 51 の近心移 動が原因と思われる歯間離開を生じた。下顎第二小 臼歯〜第二大臼歯は噛みしめ時に咬合力によって 近心方向に変位する ${ }^{1)}$ ため, 経時的に近心移動が生 じる可能性が高いと考えられ，またインプラント補綴 装置を装着された患者のうち, $1 / 3$ が半年以内に, 約 $1 / 2$ が 18 カ月という早期にインプラント部の咬合調 整を要したとの報告があり，理由の一部が天然歯の 移動と考えられている ${ }^{2)}$. 今後さらに経過を観察して いく必要がある.

\section{V. 結 論}

下顎片側遊離端欠損症例に対し，インプラントを 用いて咬合回復を行い, 長期に安定した機能改善を 罒ることができた。

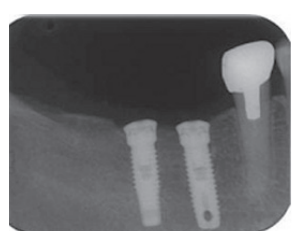

A

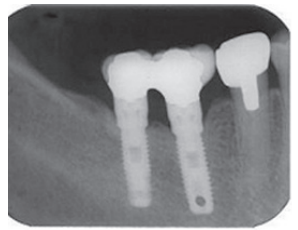

C

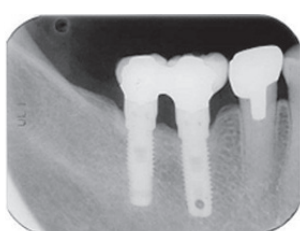

B

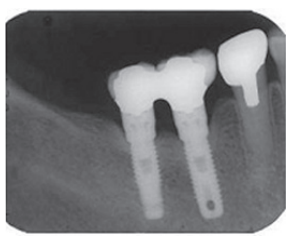

D
図 6 Radiographs at the implant installation (A), at the delivery of prosthesis (B), after 2 years and 5 months (C), and after 3 years and 2 months (D) of treatment インプラント埋入時 $(\mathrm{A})$, 補綴装置装着時 $(\mathrm{B})$, 補経 装置装着 2 年 5 力月後 $(\mathrm{C})$, および 3 年 2 力月後 $(\mathrm{D})$ のデンタルX 線写真
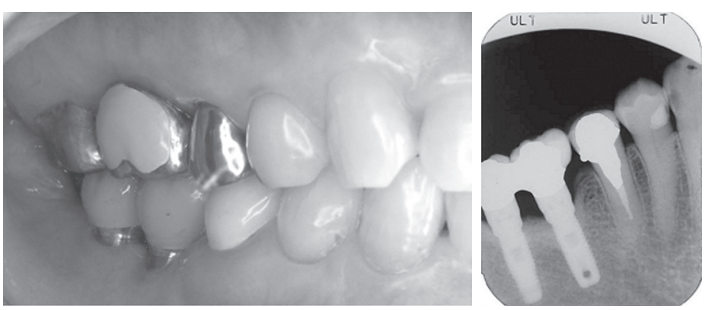

図 7 Intraoral view and radiograph at the delivery of $\overline{5}$ facing crown

5 前装鋳造冠装着時の口腔内写真およびデンタル X 線 写真

\section{文献}

1）三浦宏之. 機能下にある歯牙の水平面における変位に関 する研究. 補綴誌 1985; 29: 348-367.

2) Dario LJ. How occlusal forces change in implant patients: A clinical research report. J Am Dent Assoc 1995; 126: 1130-1133.

著者連絡先：鮎川 保則

于 812-8582 福岡市東区馬出 3-1-1

TEL : 092-642-6441

FAX : 092-642-6380

E-mail : ayukawa@dent.kyushu-u.ac.jp 